\title{
Tensile Behavior and Cracking Pattern of an Ultra-High Performance Mortar Reinforced by Polyethylene Fiber
}

\author{
Jeong-Il Choi, ${ }^{1}$ Seung Yup Jang, ${ }^{2}$ Seung-Jun Kwon, ${ }^{3}$ and Bang Yeon Lee ${ }^{1}$ \\ ${ }^{1}$ School of Architecture, Chonnam National University, 77 Yongbong-ro, Buk-gu, Gwangju 61186, Republic of Korea \\ ${ }^{2}$ Korea Railroad Research Institute, Cheoldobangmulgwan-ro 176, Uiwang, Gyeonggi-do 16105, Republic of Korea \\ ${ }^{3}$ Department of Civil Engineering, Hannam University, Daejeon 34430, Republic of Korea \\ Correspondence should be addressed to Bang Yeon Lee; bylee@jnu.ac.kr
}

Received 13 April 2017; Revised 14 June 2017; Accepted 2 July 2017; Published 2 August 2017

Academic Editor: Enzo Martinelli

Copyright (C) 2017 Jeong-Il Choi et al. This is an open access article distributed under the Creative Commons Attribution License, which permits unrestricted use, distribution, and reproduction in any medium, provided the original work is properly cited.

\begin{abstract}
This paper presents an experimental study of the compressive strength, tensile behavior (including the tensile strength, tensile strain capacity, and toughness), and cracking patterns of an ultra-high performance mortar (UHPM) reinforced by polyethylene (PE) fiber as well as a discussion of the different tensile behaviors of the UHPM according to the types and contents of fibers used. The UHPM reinforced by microsteel fiber of $1.5 \mathrm{vol} \%$ and the UHPM reinforced by PE fibers with three different fiber contents were designed and prepared. A series of experiments was undertaken to assess the effect of PE fiber on the properties of the UHPM. The results found a lower strength level, higher tensile strain capacity and toughness, and a larger crack width in the PE fiber-reinforced UHPM compared to microsteel fiber-reinforced UHPM. It was also demonstrated that tensile strain capacity and toughness of $4.05 \%$ and $0.454 \mathrm{MPa} \mathrm{m} / \mathrm{m}$, respectively, can be attained when using the proposed polyethylene-fiber-reinforced UHPM.
\end{abstract}

\section{Introduction}

Ultra-high performance concrete (UHPC) is considered to be one of the most promising and advanced construction materials because it has an ultra-high compressive strength exceeding $150 \mathrm{MPa}$, good self-compactibility without fiber segregation due to its low yield stress and high plastic viscosity when optimizing each component, and the mixture proportion based on packing density theory [1-4]. Although UHPC offers several advantages, it is also associated with some disadvantages, such as stringent quality control requirements, the possible corrosion of the steel fiber, and occasionally the requirement of special curing conditions. In particular, its tensile ductility is comparable to that of high-ductile fiber-reinforced composites (HDFRC). HDFRC usually show a high tensile ductility of over $2 \%$ [5-10]. On the other hand, the tensile ductility of UHPC is less than 1\% [11-13]. The main reason for the difference in the tensile ductility between UHPC and HDFRC can be attributed to the types of reinforcing fibers used. Straight microsteel fiber with a tensile strength of up to 2,400 MPa and a circular cross-section is generally used as a reinforcing fiber to offset the brittle behavior of UHPC [13], whereas synthetic fibers such as polyvinyl alcohol (PVA) or polyethylene (PE) fibers are commonly used for HDFRC.

Previous research has reported that synthetic fibers can also be applied to UHPC instead of steel fibers. Kamal et al. developed an ultra-high performance strain-hardening cementitious composite (UHP-SHCC) reinforced by PE fiber with $1.5 \mathrm{vol} \%$ [14]. The compressive strength, tensile strength, and tensile strain capacity of the UHP-SHCC at 14 days were $96 \mathrm{MPa}, 10 \mathrm{MPa}$, and $2.8 \%$, respectively. Ranade et al. also developed high-strength high-ductility concrete and reported that tensile ductility as high as $3.4 \%$ and a compressive strength of $160 \mathrm{MPa}$ can be realized by incorporating 2 vol\% of PE fiber [15]. Kang et al. reported that the tensile behavior can be improved by combining steel fiber and PE fiber [12]. Hybrid fiber-reinforced UHPC in which $33 \%$ of the steel fiber was replaced with PE fiber showed a higher tensile strength by $14 \%$ and a higher tensile strain capacity by $39 \%$ than single-type steel-fiber-reinforced UHPC. Additionally, 
TABLE 1: Chemical composition of cement and zirconia silica fume.

\begin{tabular}{lcccccccccc}
\hline Material & $\mathrm{SiO}_{2}$ & $\mathrm{Al}_{2} \mathrm{O}_{3}$ & $\mathrm{Fe}_{2} \mathrm{O}_{3}$ & $\mathrm{CaO}$ & $\mathrm{MgO}$ & $\mathrm{SO}_{3}$ & $\mathrm{TiO}_{2}$ & $\mathrm{~K}_{2} \mathrm{O}$ & $\mathrm{ZrO}_{2}$ & $\mathrm{And} \mathrm{so} \mathrm{on}$ \\
\hline Cement & 18.5 & 4.5 & 3.3 & 65.8 & 3.4 & 2.2 & 0.3 & 1.1 & - & 0.9 \\
Zirconia silica fume & 96.00 & 0.25 & 0.12 & 0.38 & 0.1 & - & - & - & 3.0 & 0.15 \\
\hline
\end{tabular}

TABle 2: Properties of the fibers.

\begin{tabular}{lcccccc}
\hline Type of fiber & Diameter $(\mu \mathrm{m})$ & Length $(\mathrm{mm})$ & Aspect ratio & Tensile strength $(\mathrm{MPa})$ & Density $\left(\mathrm{g} / \mathrm{cm}^{3}\right)$ & Elastic modulus $(\mathrm{GPa})$ \\
\hline Steel & 200 & 19.5 & 97.5 & 2,500 & 7.8 & 200 \\
PE & 32 & 12 & 375 & 2,950 & 0.97 & 110 \\
\hline
\end{tabular}

TABLE 3: Mixture proportion of material (weight ratio to cement except fiber).

\begin{tabular}{|c|c|c|c|c|c|c|c|c|c|c|}
\hline \multirow{2}{*}{ Mixture } & \multicolumn{2}{|c|}{ Binder } & \multirow{2}{*}{$w / b$} & \multirow{2}{*}{ Filler } & \multirow{2}{*}{ Silica sand } & \multirow{2}{*}{$\mathrm{EA}$} & \multirow{2}{*}{ Defoamer } & \multirow{2}{*}{ SP } & \multicolumn{2}{|c|}{ Fiber ( $\%$ by volume) } \\
\hline & $\mathrm{C}$ & SF & & & & & & & Steel & $\mathrm{PE}$ \\
\hline S1.50 & \multirow{4}{*}{1} & \multirow{4}{*}{0.25} & \multirow{4}{*}{0.2} & \multirow{4}{*}{0.3} & \multirow{4}{*}{1.1} & \multirow{4}{*}{0.075} & \multirow{4}{*}{0.0007} & 0.014 & 1.50 & \\
\hline P1.25 & & & & & & & & 0.015 & & 1.25 \\
\hline P1.50 & & & & & & & & 0.016 & & 1.50 \\
\hline $\mathrm{P} 1.75$ & & & & & & & & 0.018 & & 1.75 \\
\hline
\end{tabular}

He et al. proposed a novel method, in which UHPC was reinforced by the PE fiber coated with carbon nanofibers (CNF), to increase the interface frictional bond strength between the fiber and the matrix [16]. The UHPC incorporating CNFcoated PE fibers showed $15 \%$ enhancement in tensile strength and $20 \%$ improvement in tensile strain capacity as compared to the control UHPC.

Although it was demonstrated that the tensile behavior of UHPC can be improved by incorporating PE fiber, literature on the effects of the fiber content and the types of fibers on the mechanical behavior and cracking patterns of UHPC remains limited, and further research to improve the tensile behavior of UHPC by the combination of ultra-high performance mortar (UHPM) and PE fiber is needed.

The purpose of this study is to experimentally investigate the compressive strength, the tensile behavior, and cracking pattern of UHPM reinforced by PE fiber and to discuss the different tensile behaviors of microsteel fiber-reinforced UHPM and PE fiber-reinforced UHPM. Furthermore, the tensile behavior of UHPC investigated in this study was compared with those of UHPCs reported in literature.

\section{Materials and Methods}

2.1. Materials and Mixture Proportion. Ordinary Portland cement (C) and zirconia silica fume (SF) were used together as a binder. The specific surface area of the SF was $8 \mathrm{~m}^{2} / \mathrm{g}$, and it consisted of more than $96 \%$ of $\mathrm{SiO}_{2}$. The chemical composition of the binder is listed in Table 1 . The filler was pure silica with an average diameter of $2.2 \mu \mathrm{m}$. It consisted of more than $99 \%$ of $\mathrm{SiO}_{2}$. It was adopted to maximize the packing density, and its use improved the flowability and increased the compressive strength. Silica sand with an average diameter of $500 \mu \mathrm{m}$ was used as a fine aggregate to increase the stiffness and decrease the degree of shrinkage. Large aggregate was excluded to improve the fiber dispersion and decrease the fracture toughness of the matrix. Expansive admixture (EA) was used to decrease the shrinkage. A defoamer was used to minimize the unintentional air bubbles which can form during the mixing process. The amount of superplasticizer (SP) was optimized according to the types of reinforcing fibers. Steel fiber and PE fiber were used as reinforcing fibers. The dimensions and physical properties of the fibers are listed in Table 2.

Table 3 lists the mixture proportions of materials investigated in this study. The S1.50 mixture is a control mixture and contains $1.50 \mathrm{vol} \%$ of microsteel fiber. Three different fiber volume fractions of PE fibers were determined to evaluate the effectiveness of the contents of PE fibers in the mechanical properties and cracking patterns of UHPM reinforced by $\mathrm{PE}$ fiber. The mixture proportion of mortar was designed to achieve the maximum packing density and a high compressive strength of up to $150 \mathrm{MPa}$ at 28 days when cured in water at a temperature of $23^{\circ} \mathrm{C} \pm 3^{\circ} \mathrm{C}$ and high flowability with high plastic viscosity. This was done to prevent segregation or sedimentation of the steel fiber $[11,12]$. The water-to-binder ratio $(w / b)$ was fixed at 0.2 for all mixtures. In the mix design procedure, particle packing theory was applied to achieve the maximum packing density of mortar. Figure 1 shows the particle size distribution of solid constituents used in this study and that predicted by the modified Andreasen and Andersen model [17].

2.2. Specimen Preparation. A planetary mixer was used to mix all mixtures. The powder-type components, that is, binder, filler, silica sand, and expansive agent, were mixed at a speed of $90 \mathrm{rpm}$ for ten minutes. Subsequently, the liquid-type ingredients, that is, in this case the water, SP, 
TABLE 4: Density and compressive strength of each mixture.

\begin{tabular}{lccc}
\hline Mixture & Density $\left(\mathrm{g} / \mathrm{cm}^{3}\right)$ & Theoretical & Compressive strength $(\mathrm{MPa})$ \\
\hline S1.50 & Measured & 2.45 & $151 \pm 6.3$ \\
P1.25 & $2.41 \pm 0.07$ & 2.36 & $125 \pm 4.9$ \\
P1.50 & $2.34 \pm 0.01$ & 2.35 & $124 \pm 2.9$ \\
P1.75 & $2.34 \pm 0.01$ & 2.35 & $124 \pm 3.2$ \\
\hline
\end{tabular}

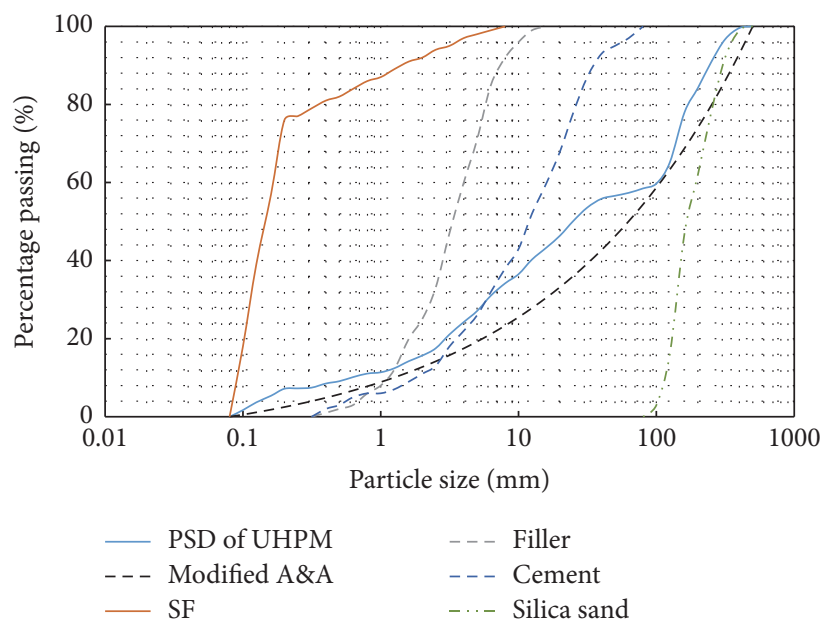

FIGURE 1: Particle size distribution of the solid constituents used in this study.

and defoamer, were put into the mixer and the mixture was mixed at the same speed for another five minutes until it was changed from a powder to a viscoplastic liquid. Lastly, the fibers were inserted into the mixer and the mixture was mixed for five minutes. During this process, additional SP, if necessary, was added to disperse the fibers suitably and to ensure proper rheological properties of the mixture. After mixing, all mixtures were poured into a mold. For each mixture, six $50 \mathrm{~mm}$ cube specimens were formulated for density and compressive tests, and five dog-bone shaped specimens as specified in the recommendations of the Japan Society of Civil Engineers [18] were created for uniaxial tension tests. All molds with mixtures were covered with plastic sheets and all mixtures were cured in air at a temperature of $23^{\circ} \mathrm{C} \pm 3^{\circ} \mathrm{C}$. The mold was demolded after two days from the casting, and all mixtures were cured in water at a temperature of $23^{\circ} \mathrm{C} \pm$ $3^{\circ} \mathrm{C}$ until reaching an age of 28 days.

2.3. Density Test. The density of each mixture was obtained by measuring the weights of the specimens in air and in water. The test was performed at 28 days in a saturated surface dry condition, and the density was calculated from

$$
\rho=\frac{W_{A}}{W_{A}-W_{W}} \times \rho_{w} .
$$

Here, $\rho, \rho_{w}, W_{A}$, and $W_{W}$ are the density of the specimen, the density of water, the weight of the specimen in air, and the weight of the specimen in water, respectively.
2.4. Mechanical Tests. The compressive strength of each mixture was measured in accordance with ASTM C109 at an age of 28 days [19]. The average value and standard deviation of six specimens for each mixture were calculated. The uniaxial tension test was conducted with an electromechanical universal testing machine to investigate the tensile behavior of each mixture. The tensile load was applied to each specimen under displacement control at a loading speed of $0.1 \mathrm{~mm} / \mathrm{min}$, and the tensile load was measured by a load cell which was put between the cross-head of the machine and the grip. The elongation of the specimen during the test was measured by two linear variable differential transducers which were mounted parallel to the two side edges of the specimen, as shown in Figure 2(a). Figure 2(b) shows the dimensions of the specimen.

\section{Results and Discussion}

3.1. Density. The measured densities and theoretically calculated densities of each mixture are listed in Table 4. The theoretical density was calculated from the mixture proportion and density of each component. The maximum difference between the measured densities and the theoretically calculated densities was $1.64 \%$. These test results provide evidence that all mixtures were successfully manufactured without unintentional pores during the mixing and casting processes. The density of the P1.50 mixture, with an amount of fiber identical to that of the $\$ 1.50$ mixture, was $3.2 \%$ less 


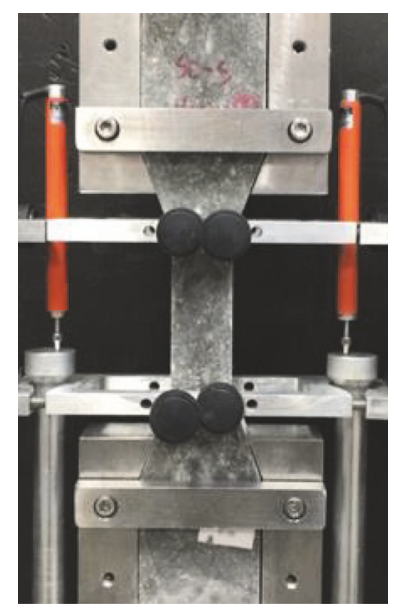

(a)

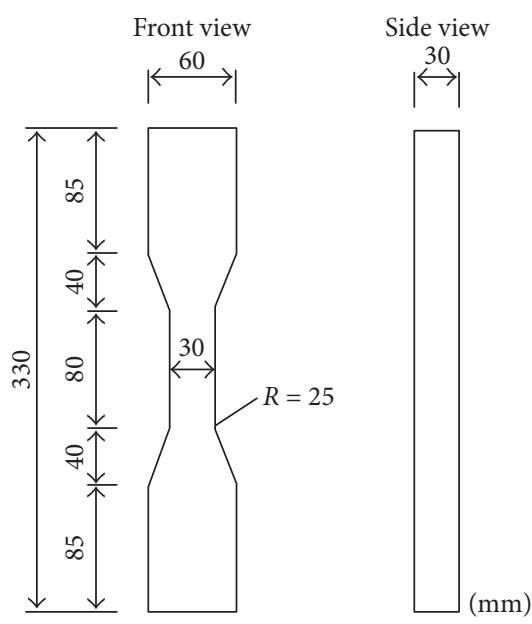

(b)

Figure 2: Uniaxial tension test: (a) the test setup and (b) the dimensions of specimen.

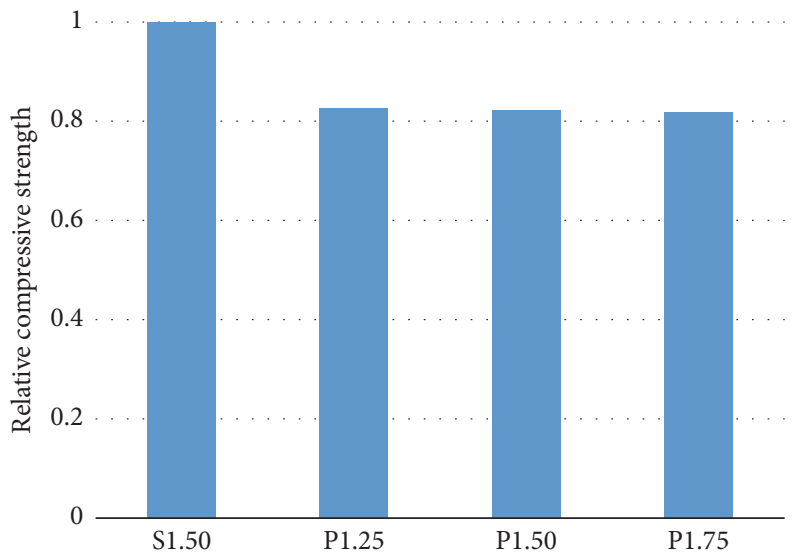

FIGURE 3: Relative compressive strength of each mixture.

than that of S1.50. This was attributed to the difference in the densities of the steel fiber and PE fiber. As can be expected, the density decreased with an increase of the amount of PE fiber.

3.2. Compressive Strength. The compressive strength $\left(f_{\mathrm{cu}}\right)$ of the $\mathrm{S} 1.50$ mixture was $151 \mathrm{MPa}$, which is $1 \mathrm{MPa}$ higher than the target compressive strength $(150 \mathrm{MPa})$. It is generally accepted that the minimum compressive strength of UHPC is $150 \mathrm{MPa}[1,2]$. Therefore, the $\mathrm{S} 1.50$ mixture, in which the UHPM was reinforced by microsteel fiber, can be classified as UHPC. The compressive strength of the P1.50 mixture, which had a fiber content identical to that of the S1.50 mixture but with a different fiber type (PE fiber), was $124 \mathrm{MPa}$, which was $17.8 \%$ lower than that of the S1.50 mixture (Table 4 and Figure 3). It was observed that the effect of the PE fiber content on the compressive strength was not significant within the range of $\mathrm{PE}$ fiber content investigated in this study. Figure 3 shows the relative compressive strength of each mixture. The $\mathrm{P}$ series mixtures showed an average compressive strength of $82 \%$ compared to S1.50 mixture.
3.3. Uniaxial Tensile Behavior. Figure 4 shows the uniaxial tensile stress and strain curves of each mixture. All mixtures showed strain-hardening behavior under uniaxial tension. However, each mixture showed quite different tensile behavior. The steel-fiber-reinforced UHPC S1.50 mixture showed a small drop in the stress level when a crack occurred along with clear strain-hardening. The strain-hardening behavior was recurrent until the tensile strain capacity corresponded to the tensile strength. On the other hand, the P series mixtures showed more of a decline in the stress level than the S1.50 mixture when a crack occurred. It is well known that a small stress drop occurs when the chemical bond and frictional bond between the fiber and the matrix are high [20]. PE fiber is hydrophobic, with little chemical bond between the fiber and the matrix. Therefore, it is generally the case that there is a relatively high stress drop when a crack occurs in a composite reinforced by PE fiber. A similar phenomenon was observed in the mixtures investigated in this study. The test results imply that there is a stronger bond between the microsteel fiber and the matrix than that by the PE fibers. Moreover, the crack opening of the PE fiber-reinforced 
TABLE 5: Uniaxial tension test results.

\begin{tabular}{lcccc}
\hline Mixture & First cracking strength $(\mathrm{MPa})$ & Tensile strength $(\mathrm{MPa})$ & Tensile strain capacity $(\%)$ & Toughness $(\mathrm{MPa}$ m/m) \\
\hline S1.50 & $13.24 \pm 1.62$ & $19.46 \pm 0.83$ & $0.85 \pm 0.21$ & 0.139 \\
P1.25 & $7.65 \pm 2.30$ & $11.42 \pm 0.77$ & $1.24 \pm 0.44$ & 0.117 \\
P1.50 & $8.35 \pm 1.49$ & $12.90 \pm 0.58$ & $3.70 \pm 1.35$ & 0.393 \\
P1.75 & $7.83 \pm 1.09$ & $14.60 \pm 0.62$ & $4.05 \pm 0.79$ & 0.454 \\
\hline
\end{tabular}

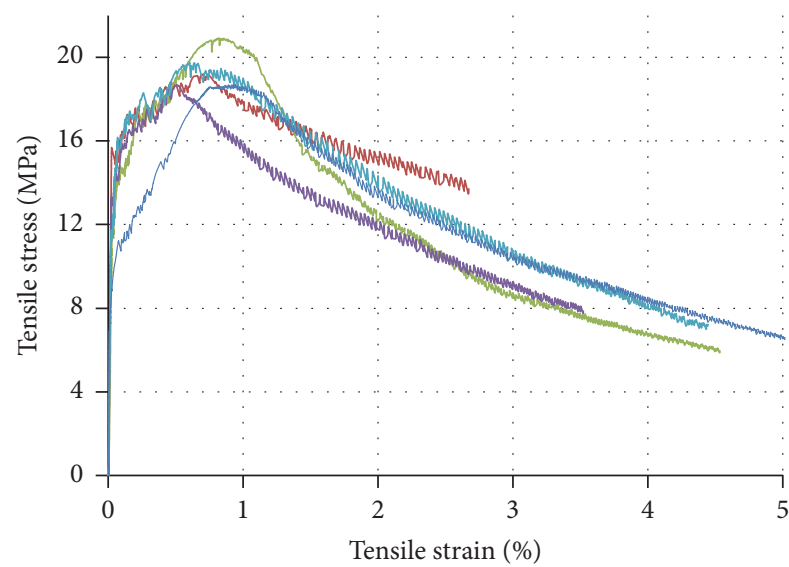

(a)

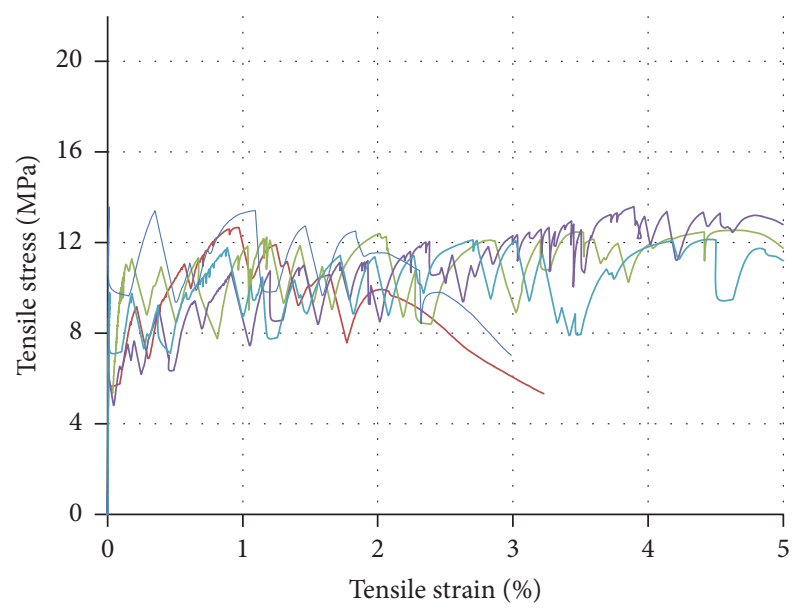

(c)

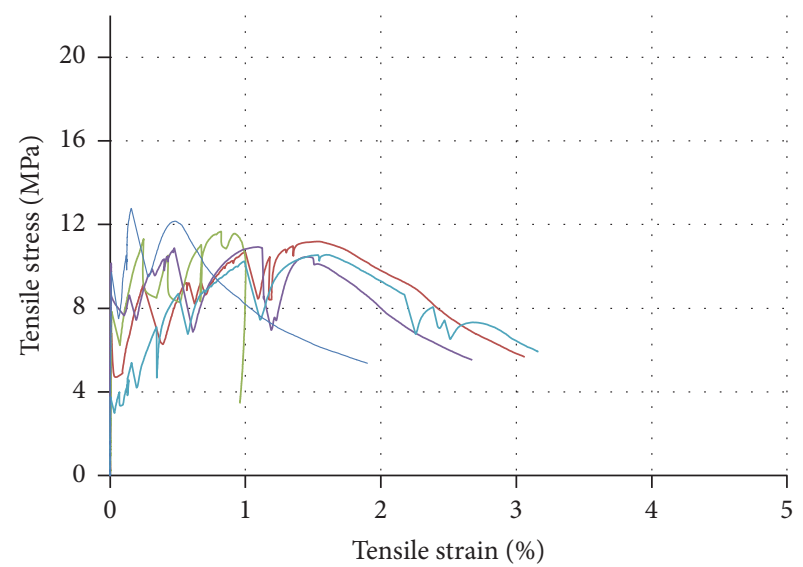

(b)

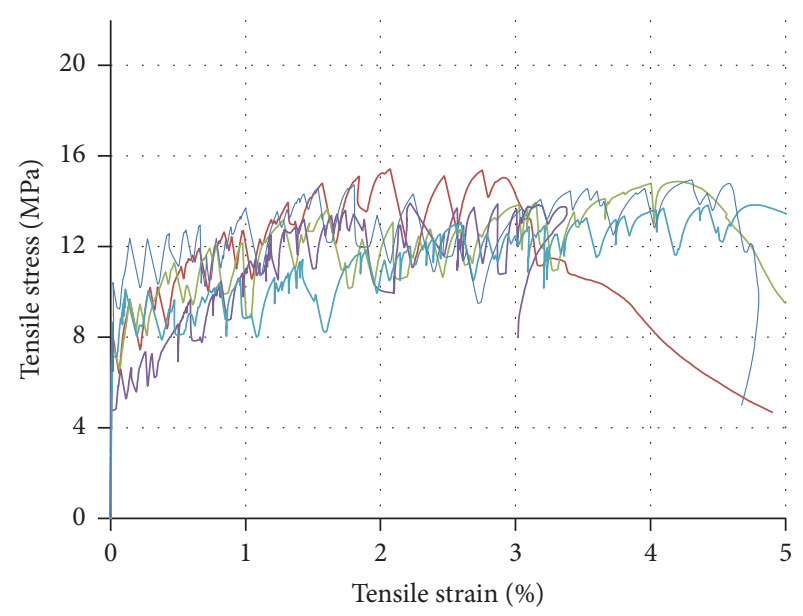

(d)

Figure 4: Uniaxial tensile stress and strain curves: (a) S1.50, (b) P1.25, (c) P1.50, and (d) P1.75 (Note. Strain valid up to tensile strength only).

system corresponding to the maximum fiber bridging stress is larger than that of the steel-fiber-reinforced system, which will be discussed later in relation to the cracking pattern.

Table 5 lists the first cracking strength $\left(f_{1 \text { st }}\right)$, tensile strength $\left(f_{t}\right)$, tensile strain capacity, and toughness of each mixture. The tensile strength and tensile strain capacity were defined as the maximum tensile stress and tensile strain corresponding to maximum tensile stress of each specimen, respectively. Toughness was defined as an area of the tensile stress and strain curves until the tensile strength. Figure 5 shows the comparison of the tensile stress and strain curves of four mixtures. As shown in this figure, the P1.50 and P1.75 mixtures show superior tensile ductility, that is, high tensile strain capacity and toughness compared to the S1.50 and P1.25 mixtures.

The first cracking strength of the P1.50 mixture was $36.9 \%$ lower than that of the S1.50 mixture, whereas the effect of the fiber content on the first cracking strength was not significant. The differences in the first cracking strength between all $\mathrm{P}$ series mixtures were within the standard deviation. Figure 6 shows the ratio of $f_{1 \text { st }}$ to $f_{\text {cu }}$ of each mixture. The ratio of $f_{1 \text { st }}$ to $f_{\text {cu }}$ of $S 1.50$ was $8.8 \%$, which was higher than those of the $\mathrm{P}$ series mixtures. It was observed that the decrease in the first cracking strength by PE reinforcement was greater than the decrease in the compressive strength. 


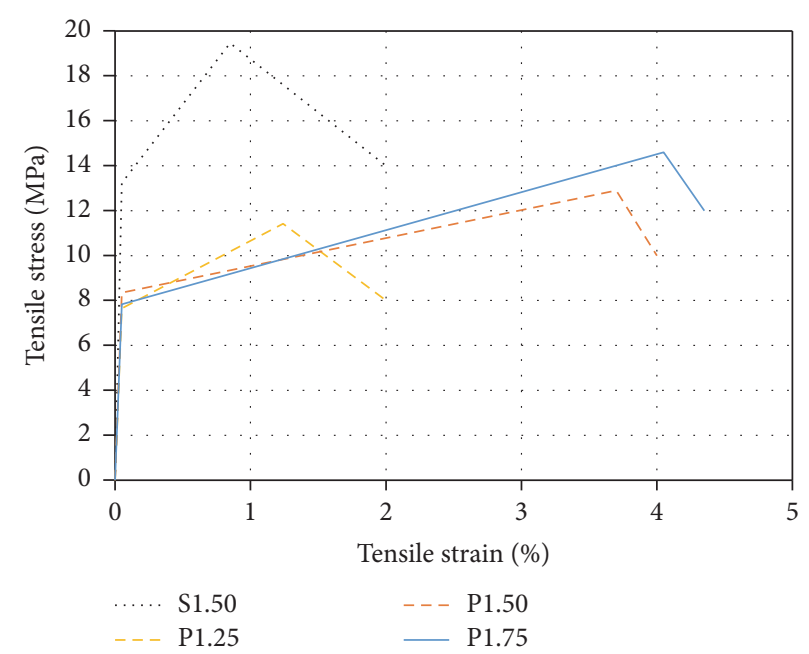

FIGURE 5: Comparison diagram of the tensile stress and strain curves.
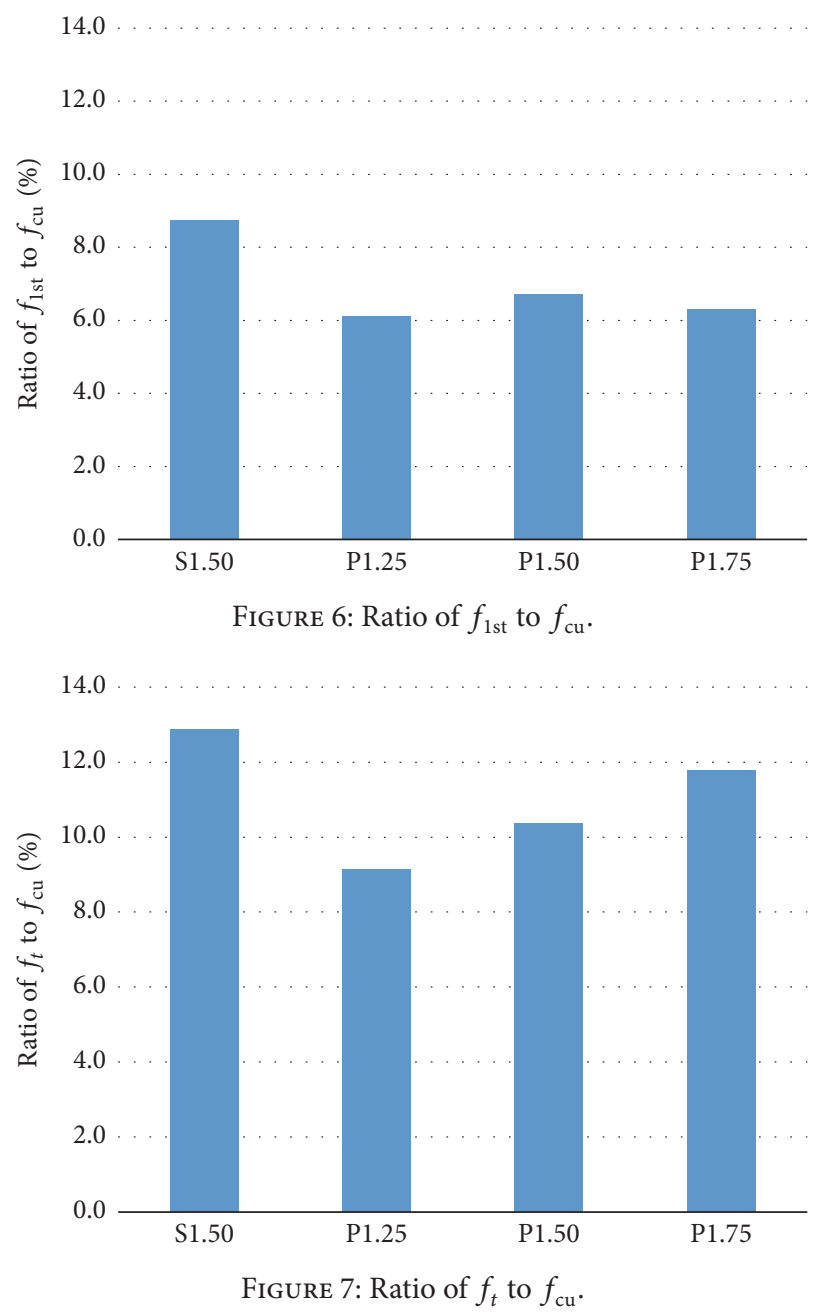

The tensile strength of the P1.50 mixture was $33.7 \%$ lower than that of the S1.50 mixture. Although the effect of the fiber content on the first cracking strength was not significant, the tensile strength of the $\mathrm{P}$ series mixture increased with an increase in the fiber content. This phenomenon can be observed in Figure 7 where the ratio of $f_{t}$ to $f_{\text {cu }}$ is presented.

Figure 8 shows the ratio of $f_{t}$ to $f_{1 \mathrm{st}}$. The ratios of $f_{t}$ to $f_{1 \mathrm{st}}$ of all $\mathrm{P}$ series mixtures were higher than that of the S1.50 


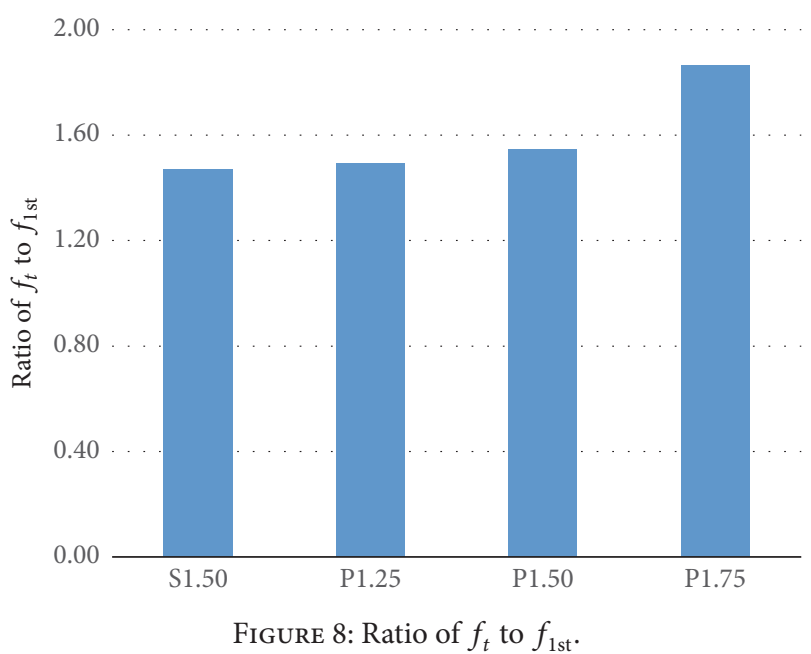

mixture, and they increased with an increase in the fiber content. Kanda and Li proposed practical design criteria for the stress and energy levels and two performance indices (the stress performance and the energy performance indices) for saturated pseudo strain-hardening behavior [21]. The stress performance index, which can be quantitatively expressed by the ratio of $f_{t}$ to $f_{1 \mathrm{st}}$, should be greater than 1 for multiple cracking behavior. The higher the performance index, the higher the probability of saturated pseudo strain-hardening behavior.

Regardless of the compressive strength and the tensile strength, the tensile strain capacity of all mixtures increased with an increase in the stress performance index. The tensile strain capacity of the P1.50 mixture was 335\% higher than that of the S1.50 mixture. Although the P1.50 mixture showed lower compressive strength and tensile strength levels than the S1.50 mixture, the P1.50 mixture showed a much greater rate of increase in the tensile strain capacity and toughness compared to the rate of decrease in the strength. The toughness of P1.50 was $182 \%$ higher than that of S1.50. The tensile strain capacity and toughness increased with an increase in the fiber content.

Figure 9 shows the comparison of the tensile stress and strain curves of the P1.75 mixture. As shown in this figure, the P1.75 mixture shows excellent tensile performance in terms of tensile strain capacity and toughness levels. The P1.75 mixture has higher tensile strain capacity by $45 \%, 19 \%$, and $76 \%$ compared to those of UHP-SHCC, HSHD concrete, and CNF-SHUHPC, respectively [14-16]. In addition, the P1.75 mixture showed higher toughness by $102 \%, 17 \%$, and $66 \%$ compared to those of UHP-SHCC, HSHD concrete, and CNF-SHUHPC, respectively. Overall, the UHPC investigated in this study exhibited better tensile performance compared with previous studies.

Figure 10 shows representative cracking patterns of each mixture. Although all mixtures showed multiple cracking behavior, there were fewer cracks in the composite investigated in this study (S1.50) compared to those in HDFRC. The cracking patterns, which can be quantitatively expressed by the number of cracks within the gauge length, crack width, and crack spacing, are shown in Figure 11. The number of cracks was manually counted on each specimen within the gauge length. The crack width was calculated from the amount of deformation and the number of cracks within the gauge length. It was assumed that all instances of deformation occurred at cracks, as the elastic deformation of the matrix was much smaller than the crack opening, induced by the fiber pullout and elastic deformation of the fiber. The crack width was identical to the crack opening, corresponding to the maximum fiber bridging stress in the fiber bridging curves. The crack spacing was calculated from the number of cracks and the gauge length.

The P1.25 and P1.50 mixtures correspondingly showed fewer cracks by $62.9 \%$ and $17.8 \%$ than the $\$ 1.50$ mixture. On the other hand, the P1.75 mixture showed more cracks by $16.9 \%$ than the S1.50 mixture. The average crack width of the S1.50 mixture was $31.9 \mu \mathrm{m}$. On the other hand, the P series mixtures showed relatively large crack widths exceeding $120 \mu \mathrm{m}$. From these test results, the fiber bridging behavior of the P series mixtures is shown to be quite different from that of the S1.50 mixture. In particular, the crack opening corresponding to the maximum fiber bridging stress of the $\mathrm{P}$ series mixtures is much larger than that of the S1.50 mixture. All P series mixtures showed higher tensile strain capacities than the S1.50 mixture. The reason for the higher tensile strain capacities of the P series mixtures compared to that of S1.50 mixture was that the crack widths of the P series mixtures were larger than those of the S1.50 mixture.

The P1.50 mixture showed larger crack spacing by $46.3 \%$ than the S1.50 mixture. This is attributed to the fact that there were fewer cracks in the P1.50 mixture than in the S1.50 mixture. As can be expected from the number of cracks, the average crack spacing of the $P$ series mixtures decreased with an increase in the fiber content.

The $\mathrm{P}$ series mixtures showed a larger standard deviation in the cracking patterns than the S1.50 mixture, and the $\mathrm{P}$ series mixtures showed worse cracking patterns than the S1.50 mixture in terms of durability because the $\mathrm{P}$ series mixtures showed larger crack widths. A large crack width induces high water and gas permeability, which results in the acceleration of ion and gas penetration. Previous work reported that the water permeability of a cementitious composite with a crack width below approximately $60 \mu \mathrm{m}$ is similar to that of a cementitious composite without cracks [22]. In addition, the diffusion coefficient of composite concrete with a crack width in the range of $55 \mu \mathrm{m} \sim 80 \mu \mathrm{m}$ was reported to be nearly identical to a concrete without cracks $[23,24]$. Although the $\$ 1.50$ mixture has the corrosion potential of steel fiber compared with the P series mixtures, the permeability of the S1.50 mixture will be much lower than that of the $P$ series mixtures.

Overall, PE fiber-reinforced UHPM showed lower strength, higher tensile strain capacity and toughness levels, and worse cracking patterns than the microsteel fiber-reinforced UHPM, and the composite properties of the PE fiber-reinforced UHPM improved as the fiber content increased. 


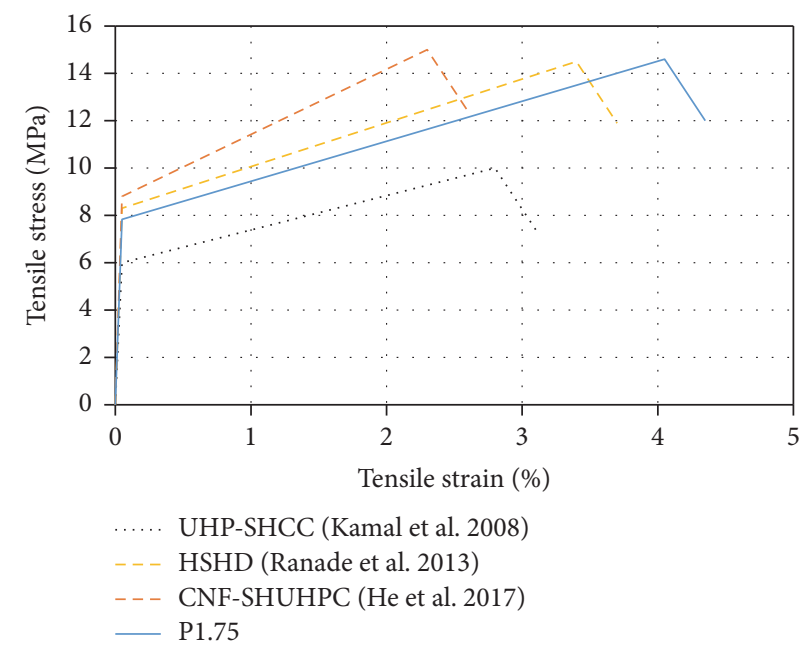

FIgURE 9: Comparison diagram of PE fiber-reinforced UHPC.

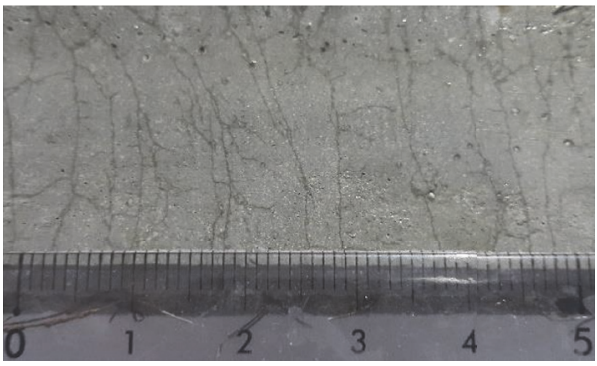

(a)

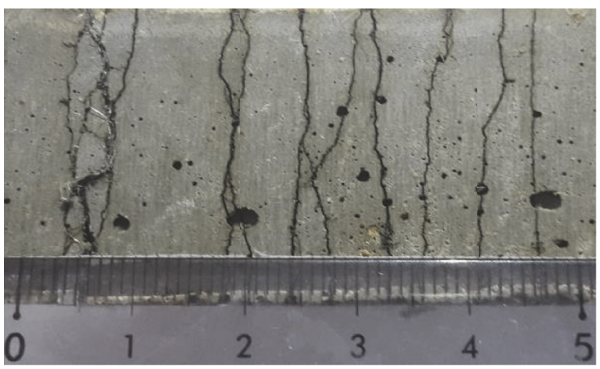

(c)

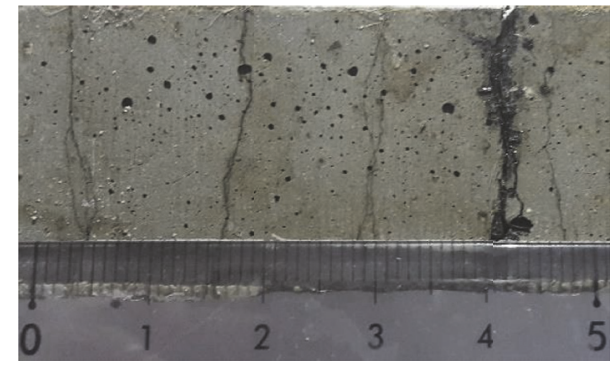

(b)

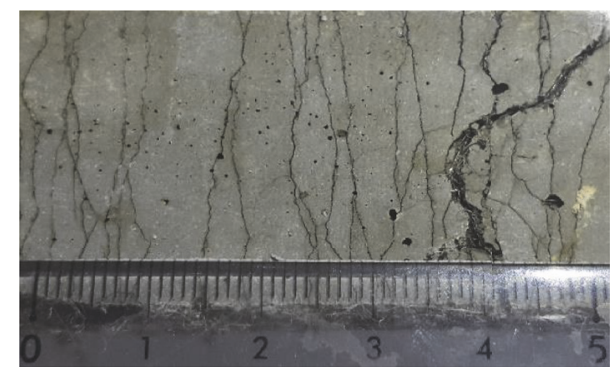

(d)

FIGURE 10: Cracking pattern (unit of numbers: cm) of (a) S1.50, (b) P1.25, (c) P1.50, and (d) P1.75.

\section{Conclusions}

This paper experimentally investigated the compressive strength and tensile behavior of UHPM reinforced by PE fiber. The following conclusions can be drawn from the results:

(1) PE fiber-reinforced UHPM showed lower compressive strength by $18 \%$ on average than microsteel fiberreinforced UHPM with an identical matrix and fiber content, and it was found that the effect of the PE fiber content on the compressive strength of UHPM was not significant within the range of the PE fiber content investigated in this study.

(2) PE fiber-reinforced UHPM showed lower first cracking strength by $40 \%$ on average than microsteel fiber-reinforced UHPM, which is a greater decrease compared to the decrease in the compressive strength. Although the effect of the fiber content on the first cracking strength was not significant, the tensile strength of the $\mathrm{P}$ series mixture increased with an increase in the fiber content. The ratios of the tensile strength to the first cracking strength of all $\mathrm{P}$ series 


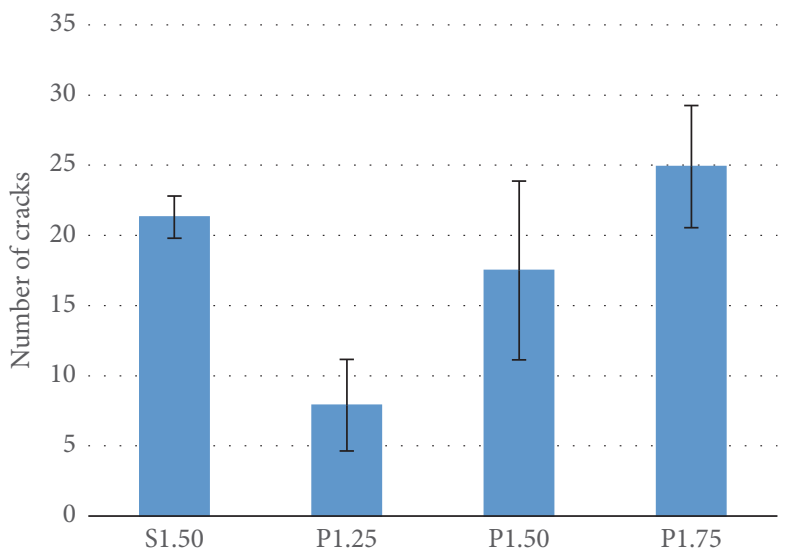

(a)

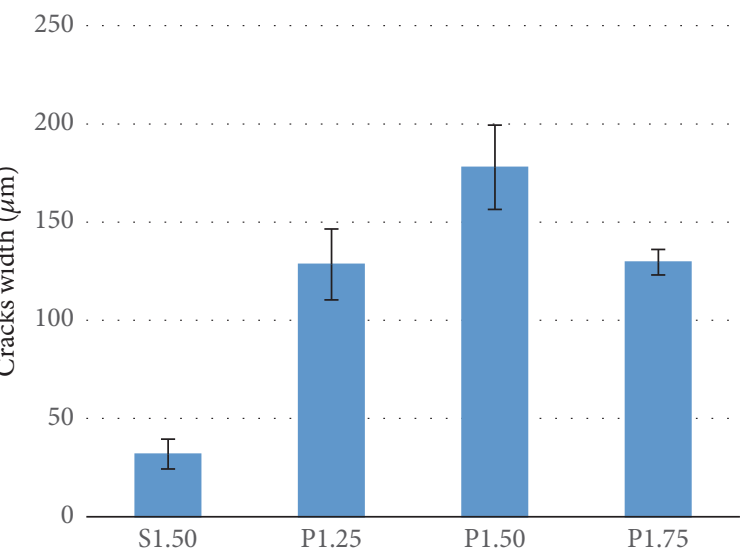

(b)

25

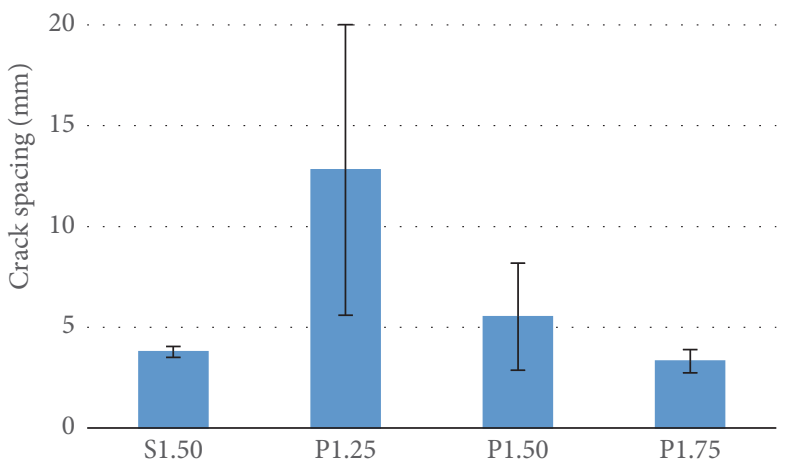

(c)

FIGURE 11: Cracking patterns (average and standard deviation): (a) number of cracks within the gauge length, (b) crack width, and (c) crack spacing.

mixtures were higher than that of the S1.50 mixture, and this ratio increased as the fiber content increased.

(3) Regardless of the compressive strength and tensile strength, the tensile strain capacity of all mixtures increased with an increase in the stress performance index. The P1.50 mixture showed a higher tensile strain capacity by $335 \%$ and greater toughness by $182 \%$ than the S1.50 mixture. However, the P1.50 mixture showed fewer cracks by $17.8 \%$ and a wider crack width by 5.6 times than the $\$ 1.50$ mixture.

(4) The P1.75 mixture with PE fiber of 1.75 vol\% showed excellent tensile performance in terms of tensile strain capacity and toughness levels. The P1.75 mixture has higher tensile strain capacity by $19 \%$ and $76 \%$ compared with HSHD concrete and CNF-SHUHPC, respectively. Furthermore, the P1.75 mixture showed higher toughness by $17 \%$ and $66 \%$ compared with HSHD concrete and CNF-SHUHPC, respectively.

\section{Conflicts of Interest}

The authors declare that they have no conflicts of interest.

\section{Acknowledgments}

This research was supported by a Grant 13SCIPA02 from Smart Civil Infrastructure Research Program and a Grant 17SCIP-B103706-03 from Construction Technology Research Program funded by Ministry of Land, Infrastructure and Transport of Korean Government and Korea Agency for Infrastructure Technology Advancement (KAIA).

\section{References}

[1] AFGC, Ultra-high performance fibre-reinforced concrete-interim recommendations, Association Française de Génie Civil, Paris, France, 2002.

[2] H. G. Russell and B. A. Graybeal, Ultra-high performance concrete: a state-of-the-art report for the bridge community, 2013.

[3] M. Špak, M. Kozlovská, Z. Struková, and R. Bašková, “Comparison of conventional and advanced concrete technologies in terms of construction efficiency," Advances in Materials Science and Engineering, vol. 2016, 6 pages, 2016.

[4] Z. Zhu, B. Li, and M. Zhou, "The influences of iron ore tailings as fine aggregate on the strength of ultra-high performance 
concrete," Advances in Materials Science and Engineering, vol. 2015, Article ID 412878, 6 pages, 2015.

[5] J.-I. Choi, K.-I. Song, J.-K. Song, and B. Y. Lee, "Composite properties of high-strength polyethylene fiber-reinforced cement and cementless composites," Composite Structures, vol. 138, pp. 116-121, 2016.

[6] M. Maalej and V. C. Li, "Flexural/tensile-strength ratio in engineered cementitious composites," Journal of Materials in Civil Engineering, vol. 6, no. 4, pp. 513-528, 1994.

[7] S.-J. Choi, J.-I. Choi, J.-K. Song, and B. Y. Lee, "Rheological and mechanical properties of fiber-reinforced alkali-activated composite," Construction and Building Materials, vol. 96, pp. 112-118, 2015.

[8] B. Y. Lee, C.-G. Cho, H.-J. Lim, J.-K. Song, K.-H. Yang, and V. C. Li, "Strain hardening fiber reinforced alkali-activated mortar - A feasibility study," Construction and Building Materials, vol. 37, pp. 15-20, 2012.

[9] V. C. Li, "Tailoring ECC for special attributes: a review," International Journal of Concrete Structures and Materials, vol. 6, no. 3, pp. 135-144, 2012.

[10] J.-I. Choi, B. Y. Lee, R. Ranade, V. C. Li, and Y. Lee, "Ultrahigh-ductile behavior of a polyethylene fiber-reinforced alkaliactivated slag-based composite," Cement and Concrete Composites, vol. 70, pp. 153-158, 2016.

[11] S.-T. Kang, K.-S. Lee, J.-I. Choi, Y. Lee, B. Felekoğlu, and B. Y. Lee, "Control of tensile behavior of ultra-high performance concrete through artificial flaws and fiber hybridization," International Journal of Concrete Structures and Materials, vol. 10, pp. 33-41, 2016.

[12] S.-T. Kang, J.-I. Choi, K.-T. Koh, K. S. Lee, and B. Y. Lee, "Hybrid effects of steel fiber and microfiber on the tensile behavior of ultra-high performance concrete," Composite Structures, vol. 145, pp. 37-42, 2016.

[13] S. H. Park, D. J. Kim, G. S. Ryu, and K. T. Koh, "Tensile behavior of ultra high performance hybrid fiber reinforced concrete," Cement and Concrete Composites, vol. 34, no. 2, pp. 172-184, 2012.

[14] A. Kamal, M. Kunieda, N. Ueda, and H. Nakamura, "Evaluation of crack opening performance of a repair material with strain hardening behavior," Cement and Concrete Composites, vol. 30, no. 10, pp. 863-871, 2008.

[15] R. Ranade, V. C. Li Prof., M. D. Stults, W. F. Heard, and T. S. Rushing, "Composite properties of high-Strength, highductility concrete," ACI Materials Journal, vol. 110, no. 4, pp. 413-422, 2013.

[16] S. He, J. Qiu, J. Li, and E. Yang, "Strain hardening ultra-high performance concrete (SHUHPC) incorporating CNF-coated polyethylene fibers," Cement and Concrete Research, vol. 98, pp. 50-60, 2017.

[17] J. E. Funk and D. Dinger, Predictive Process Control of Crowded Particulate Suspensions: Applied to Ceramic Manufacturing, Springer Science \& Business Media, 2013.

[18] JSCE, Recommendations for Design and Construction of High Performance Fiber Reinforced Cement Composites with Multiple Fine Cracks (HPFRCC), Concrete Engineering Series, Japan Society of Civil Engineers, Japan, 2008.

[19] "ASTM Standard test method for compressive strength of hydraulic cement mortars (Using 2-in. or [50-mm] cube specimens). ASTM International West Conshohocken, PA (2007)".

[20] E.-H. Yang, Y. Yang, and V. C. Li, "Use of high volumes of fly ash to improve ECC mechanical properties and material greenness," ACI Materials Journal, vol. 104, no. 6, pp. 620-628, 2007.
[21] T. Kanda and V. C. Li, "Practical design criteria for saturated pseudo strain hardening behavior in ECC," Journal of Advanced Concrete Technology, vol. 4, no. 1, pp. 59-72, 2006.

[22] M. D. Lepech and V. C. Li, "Water permeability of engineered cementitious composites," Cement and Concrete Composites, vol. 31, no. 10, pp. 744-753, 2009.

[23] R. Gagné, R. François, and P. Masse, "Chloride penetration testing of cracked mortar samples. Concrete under severe conditions 1, 198-205".

[24] S. Y. Jang, B. S. Kim, and B. H. Oh, "Effect of crack width on chloride diffusion coefficients of concrete by steady-state migration tests," Cement and Concrete Research, vol. 41, no. 1, pp. 9-19, 2011. 

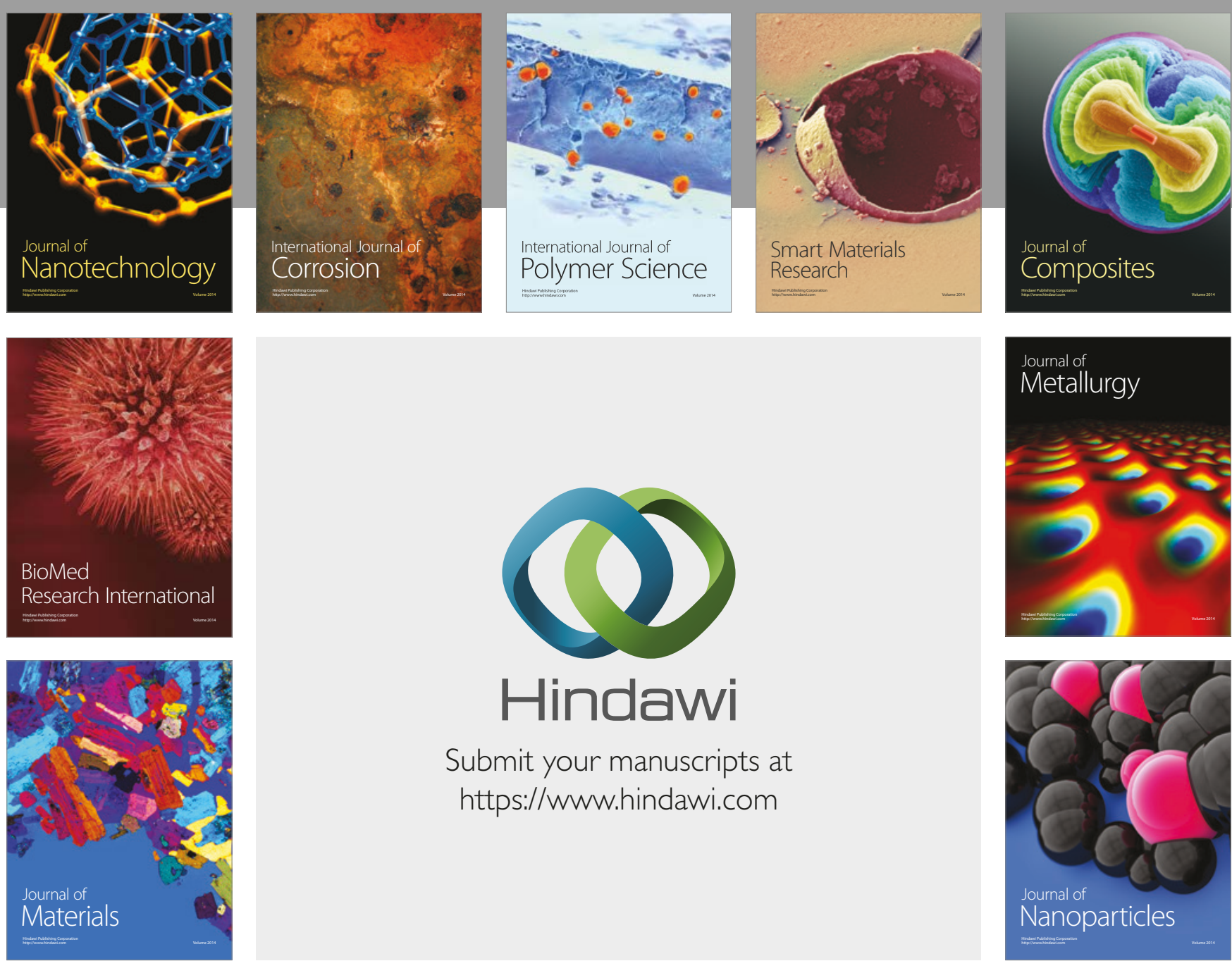

\section{Hindawi}

Submit your manuscripts at

https://www.hindawi.com
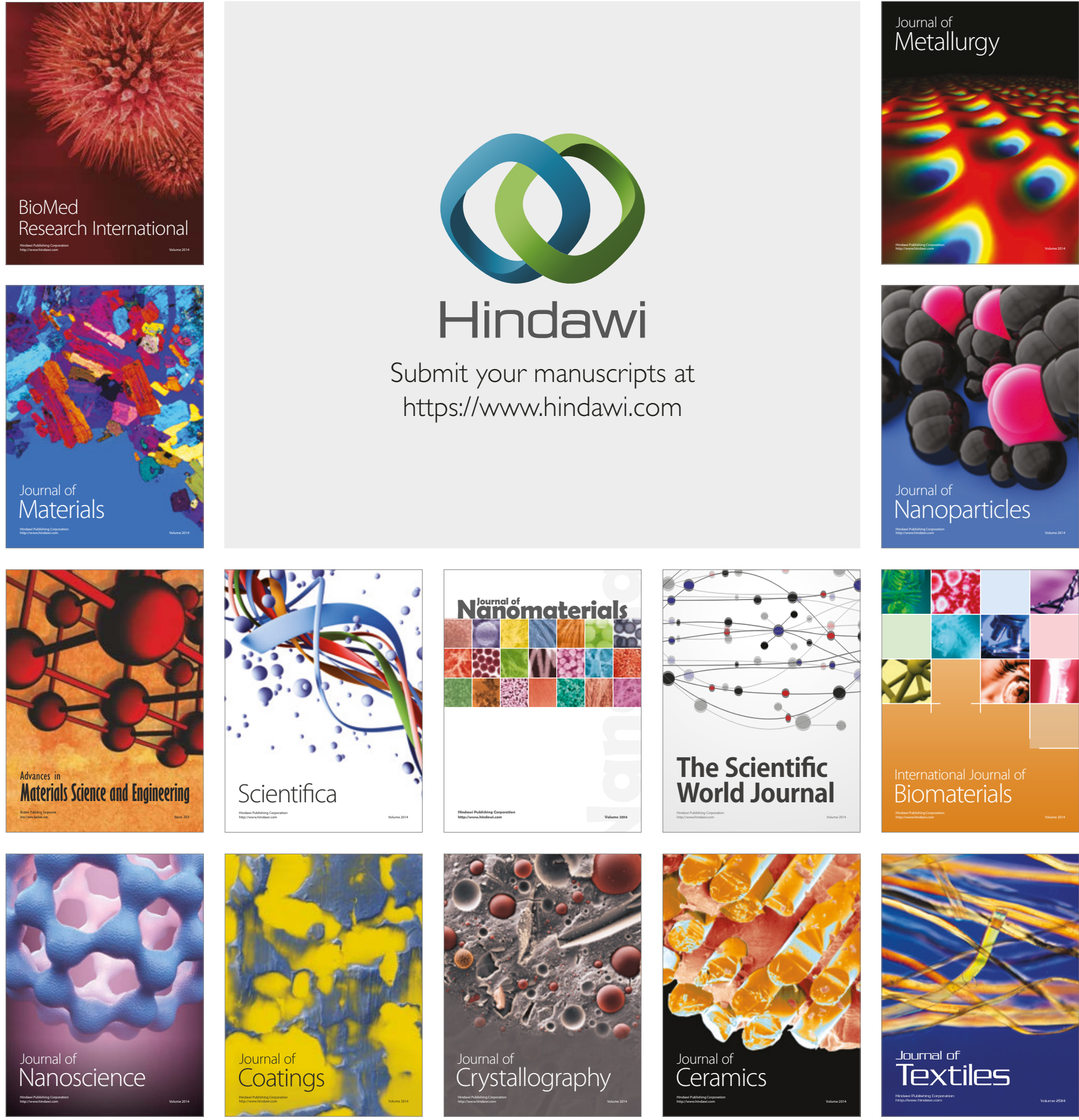

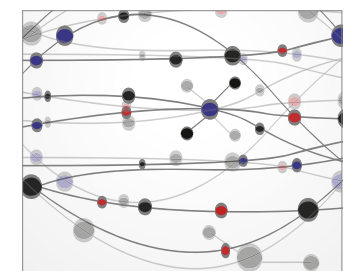

The Scientific World Journal
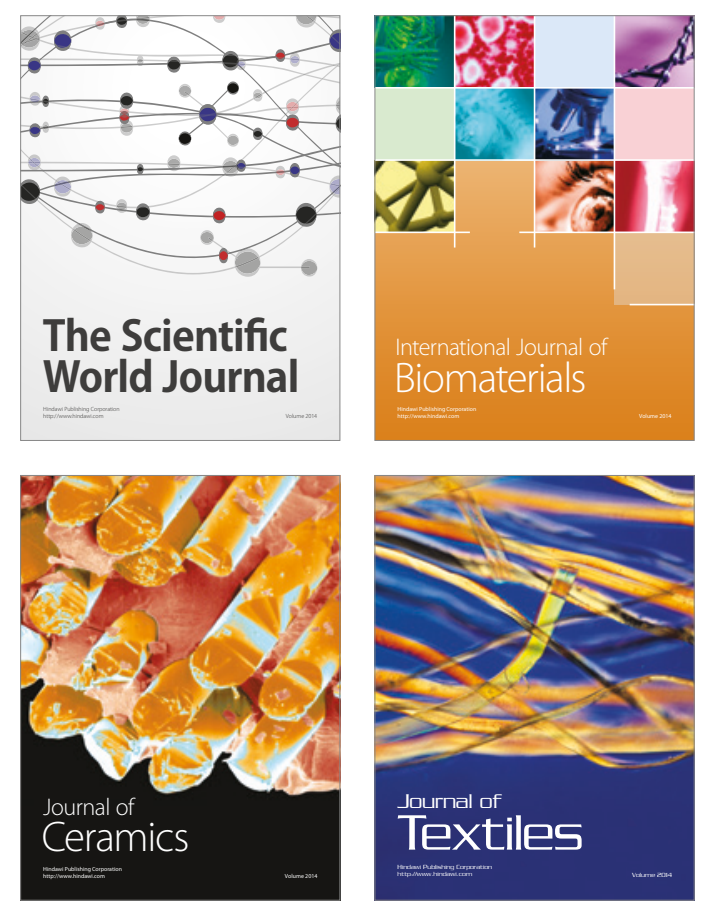